\title{
Correction to: Sol-gel synthesis of iodosodalite precursors and subsequent consolidation with a glass binder made from oxides and sol-gel routes
}

Jared O. Kroll ${ }^{1,2} \cdot$ Brian J. Riley $\mathbb{1}^{1,2} \cdot$ John S. McCloy ${ }^{1,2} \cdot$ Jacob A. Peterson $^{1}$

Published online: 13 March 2021

(c) Springer Science+Business Media, LLC, part of Springer Nature 2021

Correction to: Journal of Sol-Gel Science and Technology

https://doi.org/10.1007/s10971-020-05348-2

The original version of this article contained a mistake in the graphical abstract image. The correct graphical abstract image is given below. The original article has been corrected.

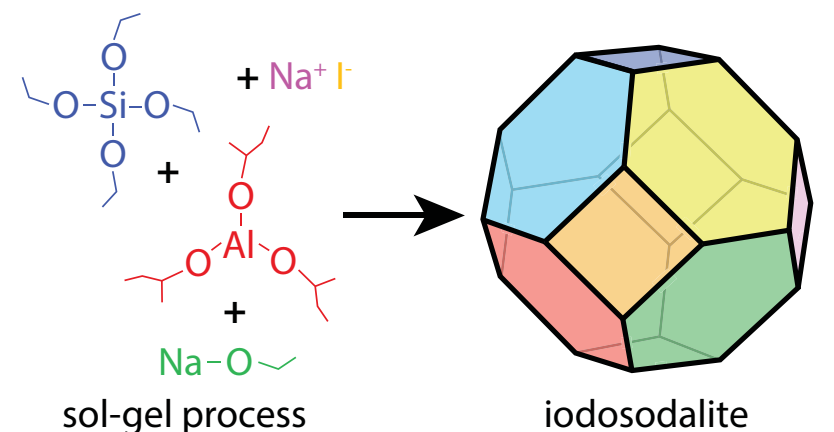

The original article can be found online at https://doi.org/10.1007/ s10971-020-05348-2.

Brian J. Riley

brian.riley@pnnl.gov

1 Pacific Northwest National Laboratory, Richland, WA 99354,

USA

2 Washington State University, Pullman, WA 99164, USA 